\title{
AS CONTRIBUIÇÕES DE PAULO FREIRE A UMA EDUCAÇÃO CIENTÍFICA NA FORMAÇÃO DOCENTE
}

\author{
Amarildo Menezes Gonzaga - Professor Doutor da Pós- \\ graduação em Ensino de Ciências na Amazônia - Universidade \\ do Estado do Amazonas-UEA \\ amarildogonzaga@yahoo.com.br \\ Caroline Barroncas de Oliveira - Bolsista Doutorado \\ FAPEAM/CNPq - Universidade Federal de Uberlândia-UFU - \\ carol_barroncas@yahoo.com.br
}

\begin{abstract}
RESUMO Este trabalho trata de um trabalho teórico que versa sobre as contribuições de Paulo Freire a uma Educação Científica na formação docente. Mostra-se que a escola contribui para a reprodução da estrutura da sociedade, quando no desenvolvimento do currículo dissemina uma monocultura escolar. Desta forma, o ensino que temos conduz os sujeitos a continuarem cada vez mais dominados para aceitarem as relações de desigualdade. Percebe-se a urgência em se romper com um ensino memorístico, que as academias privilegiem a formação e não se reduza a informação, e que a ciência seja compreendida como uma forma de ver o mundo. A inconclusão do ser, a inserção dos saberes científicos na prática social, a presença do outro e de sua palavra, a pronunciar e transformar o mundo, são elementos da pedagogia freireana que qualificam nossa compreensão de Educação Científica. Em uma Educação Científica suficientemente capaz de se aproximar das particularidades do ensino e das expectativas geradas para um público, vislumbramos uma educação formadora, em que o sujeito é capaz de dialogar com as informações científicas que norteiam seu contexto de vida. Os conceitos e conteúdos são carregados de sentido e significados, eles não se fecham em delimitações conceituais desconectados do todo. Assim, uma Educação Científica de professores privilegia primeiramente uma abertura para a compreensão desses conceitos científicos em constante processo de reelaboração e ressignificação a partir de situações e contextos que dialogam e aproximam o educador e educando de seu cotidiano.
\end{abstract}

Palavras-chave: Pedagogia de Paulo Freire. Educação Científica. Formação Docente.

\begin{abstract}
This paper is a theoretical work that discusses Paulo Freire's contributions to Scientific Education in teachers training. It is shown that the school contributes to the reproduction of society structure while in its curriculum development it spreads a monocultural school system. In this way, our teaching process has led the subjects to continue increasingly dominated and to accept relationships of inequality. We can see the urgency to extinguish a kind of education where memorizing plays a big role. It is also desirable that the academies give priority to the formation of individuals and not just to the information those can get. Science should be then understood as a way of seeing the world. The unreadyness of being, the integration of scientific knowledge in social practice, the others` presence and his/hers word ruling and transforming the world are elements of Freire's pedagogy which help us to understand the scientific education. When scientific education is sufficiently able to come near teaching particularities an also to public expectations we can get a glimpse of an education which can form citizens which are subjects able to dialogue with the scientific information that guides their lives. The concepts and contents are loaded with meaning and significance, they do not get closed or are disconnected from reality. Thus, from situations and contexts that dialogue and approach the educators to students` daily life, teachers scientific education focuses primarily in an opening for the understanding of those scientific concepts in a constant process of rethinking and reframing them.
\end{abstract}

Key-words: Paulo Freire's pedagogy. Scientific Education. Teachers training. 


\section{Revista Eletrônica do Curso de Pedagogia Ttinerarius Reflectionstim

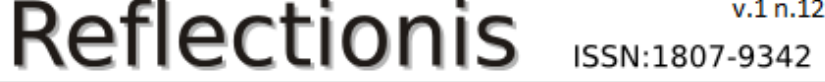

\section{Introdução}

Este trabalho é fruto de uma opção de vida no último ano do Ensino Médio, quando prestamos vestibular para o Curso Normal Superior. Ao depararmo-nos com esta natureza formativa, tivemos a oportunidade de conhecer e vivenciar a proposta de estágio articulado à pesquisa, embasada na concepção do professor-pesquisador. Durante o percurso formativo, perpassamos por caminhos tortuosos na legitimação da formação científica, pois existiam dificuldades de caráter tanto institucionais quanto pessoais. Apesar disso, tivemos outro olhar sobre o trabalho pedagógico, através do qual foi percebida a importância da Educação Científica, proporcionada na formação de professores.

A partir desta perspectiva de formação de professores, começamos a refletir sobre a importância do papel da Educação na sociedade, por meio da qual o sujeito constrói a consciência dos seus direitos como cidadão, além de criar subsídios pessoais e profissionais, atrelando-as à sua história de vida. Diante desta realidade, a Educação Científica ganha importância como parte de uma educação para todos, uma vez que, a partir dela, a população toma consciência das complexas relações entre Ciência e Sociedade, de modo a considerar a ciência como parte da cultura do nosso tempo.

A Educação Científica também possibilita-nos participar na tomada de decisões de forma crítica, tendo compreensão dos processos da ciência no mundo em que vivemos. Considerando esta possibilidade, um dos meios mais promissores de difundir a Educação Científica é por meio da escola, mudando o ensino informativo para criativo e transformador. Mas esta tarefa é difícil, e um dos vieses dependentes desta transformação é a própria formação dos professores, que têm o seu espaço de legitimação na Educação Científica.

Nesta perspectiva, surgiu este trabalho que apresenta um diálogo realizado com a teoria de Paulo Freire e suas implicações na Educação Científica e na formação docente. E para construí-lo foram realizadas leituras e fichamentos das obras de Freire (1967; 1986; 2002; 2003) objetivando ressignificar conhecimentos sobre as ideias do autor, juntamente com leituras auxiliares de obras que tratam sobre a questão da Educação Científica e Formação de Professores. 


\section{As implicações de Paulo Freire para a Educação Científica na Formação de Professores}

Esta é a possibilidade de ir além do amanhã sem ser ingenuamente idealista. [...] Antecipar o amanhã pelo sonho de hoje. A questão é o que Cabral disse: O sonho é um sonho possível ou não? Se é menos possível, trata-se, para nós, de saber como torná-lo mais possível (FREIRE, 1986).

A progressiva demonstração social da ciência ocorreu a partir das repercussões da "revolução científica" dos séculos XVI e XVII, a qual, por sua vez, integra o conjunto de transformações que tinham curso na Europa, desde o século XIV, caracterizando o fim da Idade Média e o início da Era Moderna. No plano cultural, o Humanismo e o Renascimento abriram espaço para novas indagações sobre a natureza física. Do ponto de vista político e econômico, assistiu-se então a uma verdadeira "revolução comercial" e à ascensão da classe burguesa, que iria estimular o desenvolvimento das ciências e das técnicas (ALBAGLI, 1996).

A segunda metade do século XX foi marcada pelo grande avanço na produção de novos conhecimentos e na introdução de novas tecnologias, que alteraram radicalmente os padrões estabelecidos até então, e resultaram em mudanças de amplitude global em todos os setores da sociedade. Nesse outro contexto, cresce cada vez mais a importância do papel da educação e da pesquisa científica e tecnológica para atender às necessidades e oportunidades que se apresentam a cada momento. Os instrumentos criados pelas tecnologias dependem essencialmente de recursos humanos capacitados para acessar informações e transformá-las em conhecimento e inovação (ROITMAN, 2007).

A partir do crescimento da ciência na história da humanidade, a Educação Científica da população é uma necessidade ainda mais permanente. Cada vez mais, questões ligadas à ciência fazem parte do nosso cotidiano. A discussão da necessidade da Educação Científica para todos é de épocas anteriores. O matemático e filósofo polonês Jacob Bronowsky (1908- 


\section{Revista Eletrônica do Curso de Pedagogia

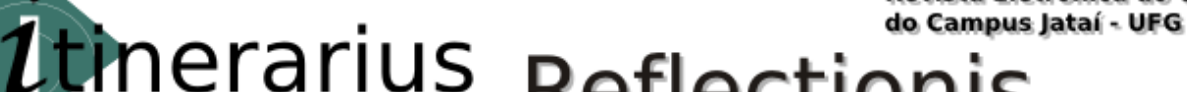 Reflectionis $155 \mathrm{~s}: 1807 \cdot 9392$}

1974) em seu livro Ciência e Valores Humanos, publicado originalmente em 1956, fez o seguinte alerta para a necessidade da Educação Científica:

[...] devemos tremer sempre que ouvimos um homem de sensibilidade considerar a ciência como um assunto que pertence à outra pessoa. Hoje em dia, o mundo é feito, é potenciado, pela ciência, e qualquer pessoa que abdique de seu interesse por ela caminha de olhos abertos para a escravatura (BRONOWSKY 1979 apud AMABIS, 2005, p. 141).

O conhecimento científico afeta de tal forma nossas vidas, que é imperativo todas as pessoas terem compreensão da natureza e dos processos da ciência, e conheçam os principais avanços nas diferentes áreas científicas, aplicando-os com bom senso. Pensar em educação científica apenas como um método para produzir mais, corresponde a uma visão empresarial que pode funcionar em curto prazo, mas que sofre de um problema básico: é possível adestrar toda uma geração a adotar certas tecnologias, mas à medida que a tecnologia evolui, essa geração terá dificuldades em absorvê-la. Já uma educação básica sólida em várias áreas, sem muita especialização, estará mais bem preparada para adaptar-se às mudanças tecnológicas que estão ocorrendo com frequência cada vez maior (GOLDEMBERG, 2005).

A Educação Científica, em conjunto com a educação social e ambiental, dá oportunidade para as crianças explorarem e entenderem o que existe ao seu redor nas diferentes dimensões: humana, social e cultural. A Educação Científica desenvolve habilidades, define conceitos e conhecimentos, estimulando a criança a observar, questionar, investigar e entender de maneira lógica os seres vivos, o meio em que vivem e os eventos do cotidiano. Além disso, estimula a curiosidade, a imaginação e o entendimento do processo de construção do conhecimento; logo, investir no conhecimento científico contribuirá para que os seus resultados estejam ao alcance de todos (ROITMAN, 2007).

A Educação Científica tem a função de desenvolver a criticidade e o pensamento lógico, capacitando o sujeito a compreender como a ciência é organizada, sua natureza, seus alcances e suas limitações. Desta forma, auxilia os cidadãos nas tomadas de decisão em uma sociedade tecnológica com base em dados e informações, levando-os a compreenderem a importância da ciência no cotidiano, além de representar uma formação de recursos humanos para as atividades de pesquisa em todos os setores profissionais. Portanto, o conhecimento 


\section{Litherar

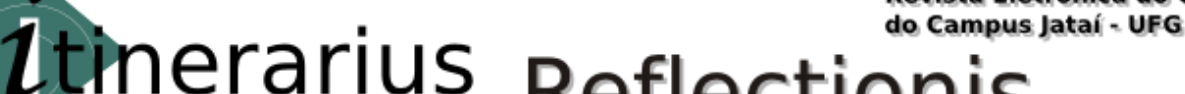

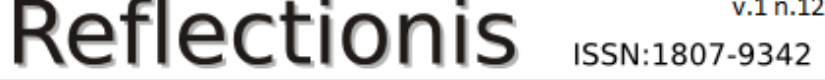

científico apresenta-se como alicerce do conhecimento, sendo considerado como a grande ferramenta para a transformação do ensino, desde que a sua apropriação e uso ocorram de modo inteligente (MOURA e VALE, 2003).

$\mathrm{Na}$ perspectiva de uma Educação Científica contextualizada e que procura valorizar saberes e conhecimentos prévios em detrimento de uma formação pautada unicamente em conteúdos científicos, Paulo Freire nos ajuda a refletir acerca do papel do educador e das características de uma prática educativa que considera o sujeito em sua integridade.

Chassot (2003), Cachapuz, Praia e Jorge (2004), Zancan (2000), entre outros, vêm discutindo veementemente que a falta de uma Educação Científica por parte dos cidadãos está colocando muitos povos à margem do conhecimento científico e tecnológico e que é necessário, em caráter de urgência, criar meios para que o conhecimento acadêmico esteja mais próximo da sociedade a fim de incluir um número cada vez maior de pessoas ao acesso do conhecimento científico.

Mas, a escola contribui para a reprodução da estrutura da sociedade, quando no desenvolvimento do currículo dissemina uma monocultura escolar, que reflete os conhecimentos e conteúdos estratificados. Essa escola, local de produção e reflexão de saberes acumulados culturalmente, muitas vezes erra ao direcionar toda sua potencialidade apenas para a transmissão desses saberes sistematizados, contribuindo, dessa forma, para a formação de um sujeito acrítico e à margem do seu papel de interagir e transformar seu contexto social, como visto nas palavras de Freire,

\footnotetext{
Uma das tarefas essenciais da escola, como centro de produção sistemática de conhecimento, é trabalhar criticamente a inteligibilidade das coisas e dos fatos e a sua comunicabilidade. [...] É preciso por outro lado e, sobretudo, que o educando vá assumindo o papel de sujeito da produção de sua inteligência do mundo e não apenas o de recebedor da que lhe seja transferida pelo professor (FREIRE, 2003, p. 124).
}

O ensino, nessa perspectiva, não é um processo unidirecional, centrado no educador e pautado na transmissão dos saberes, trata-se de uma tarefa que não se baliza em treinamentos e transferência de conhecimentos, mas sim um processo capaz de criar as possibilidades para a sua produção ou a sua construção. 


\section{1- Revista Eletrônica do Curso de Pedagogia ttinerarius Reflectionism

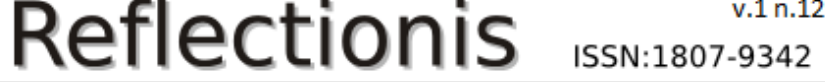

A escola, sob esse ponto de vista, não é mais o lugar da informação e da reprodução de uma ideologia dominante, a escola se constitui em um espaço aberto, onde o educando se instrumentaliza para sua transformação em desenvolvimento com a comunidade. Assim, nessa relação entre ensino, conhecimento e educando, é preciso reconhecer sob o ponto de vista do educador que se entende mediador nesse processo de ensino e aprendizagem, a importância da busca constante pela autonomia desses educandos. Para isso, é preciso "pensar certo" que nas palavras de Freire (2003) implica em um compromisso do educador com a consciência crítica desse educando, uma vez que a superação da ingenuidade não é um processo que se faz automaticamente.

Pensar certo, do ponto de vista do professor, tanto implica o respeito ao senso comum no processo de sua necessária superação quanto o respeito e o estímulo à capacidade criadora do educando (FREIRE, 2003, p. 29).

Nesse sentido, existe a responsabilidade do educador em estabelecer um compromisso ético articulado com uma educação formadora e transformadora para seu educando, nessa relação encontra-se valor na prática docente. "O ensino dos conteúdos implica o testemunho ético do professor. A boniteza da prática docente se compõe no anseio vivo de competência do docente e dos discentes e de seu sonho ético" (FREIRE, 2003, p. 95).

Uma prática educativa transformadora, fundamentada na ética, no respeito e na autonomia do educando aponta para a necessidade de, enquanto educadores, mantermos um estado constante de vigilância e compromisso contra práticas capazes de favorecer a desumanização desse sujeito.

Na busca de compor um cenário de práticas educativas capazes de dialogar com essa perspectiva de não desumanização do sujeito, onde os conteúdos sistematizados não têm fimm em si mesmos, consideramos o educando em sua totalidade, em suas emoções carregadas de sentido, reconhecendo a autonomia e capacidade desse educando em se apropriar dos saberes sistematizados sob uma lente crítica da realidade que o cerca, a fim de modificá-la.

A capacidade de aprender, não apenas para nos adaptar, mas, sobretudo para transformar a realidade, para nela intervir, recriando a, fala de nossa educabilidade a 
um nível distinto do nível do adestramento dos outros animais ou do cultivo das plantas (FREIRE, 2003, p.69).

"A prática educativa é tudo isso: afetividade, alegria, capacidade científica, domínio técnico a serviço da mudança ou, lamentavelmente, da permanência do hoje" (FREIRE, 2003, p.143). O ato de aprender nesse ponto não se constitui em transmitir, mas em uma relação de construção, de reconstrução, constatação para a mudança. Esse processo não se consolida sem a abertura ao risco e à aventura do espírito (FREIRE, 2003).

\footnotetext{
Ensinar e aprender têm que ver com o esforço metodicamente crítico do professor de desvelar a compreensão de algo e com o empenho igualmente crítico do aluno de ir entrando como sujeito em aprendizagem, no processo de desvelamento que o professor ou professora deve deflagrar (FREIRE, 2003, p.119).
}

Concordamos com as palavras de Freire, ao compreendermos que esse processo de ensino e aprendizagem não se faz pela neutralidade, há cumplicidade entre os atores e dessa maneira a prática educativa se constitui em um exercício conjunto e de aprendizagens recíprocas, intermediadas por artefatos e tecnologias a favor do desenvolvimento da autonomia de educadores e educandos.

Em uma relação dialógica e autônoma entre educadores e educandos e em condições de aprendizagem verdadeiras, "os educandos vão se transformando em reais sujeitos da construção e da reconstrução do saber ensinado, ao lado do educador, igualmente sujeito do processo" (FREIRE, 2003, p.26).

Os educandos devem identificar em sua própria realidade social a medida para não serem determinados pela História em contexto de vida. Em tempos de interesses plurais, em tempo de tecnologias e produtividades, é possível transitar criticamente entre conceitos e sentidos, o que nas palavras de Paulo Freire, significa:

[...] reconhecer que somos seres condicionados, mas não determinados. Reconhecer que a História é tempo de possibilidade e não de determinismo, que o futuro, permita-se-me reiterar, é problemático e não inexorável (FREIRE, 2003, p.19). 


\section{Revista Eletrônica do Curso de Pedagogia Reflectionis 1 iss: $1800 \cdot 9342$}

É no partir da realidade do educando que as propostas de ensino podem se consolidar em práticas transformadoras que propiciam a libertação do indivíduo. O educador precisa, sobretudo, fazer uso dessa realidade na composição de um cenário favorável ao ensino e ao aprendizado.

Assim, as propostas educativas devem favorecer a inserção do sujeito no mundo, em contraposição a um modelo de adaptação e objetivação desse indivíduo em um contexto de vida determinado pela História. Freire (2003) reitera que [...] "minha presença no mundo não é a de quem a ele se adapta, mas a de quem nele se insere. É a posição de quem luta para não ser apenas objeto, mas sujeito também da História" (FREIRE, 2003, p. 54).

Dessa maneira, é preciso conceber que a partir da inconclusão dos indivíduos, homens e mulheres, em um mundo de constante reconstrução, oportunizamos o fazer com que a educação aproprie-se de seu sentido em produzir conhecimento.

A prática educativa que se constitui a partir de conteúdos significativos com vistas à compreensão crítica da realidade, não se faz a parte da intencionalidade política e do seu comprometimento com a transformação social. Nessa perspectiva, Collins (1999), Ziman (1999), Vilanova e Martins (2008) compreendem que a Educação Científica não é uma questão somente para a comunidade científica preocupar-se, mas uma questão de política pública, pois se deposita alta carga de responsabilidade à escola enquanto lugar onde o saber sistematizado é desenvolvido e construído em vez de somente "repassado", sem cogitar sobre a que política este modelo de educação está atendendo.

Nesse contexto, Zancan (2000, p. 6) defende que,

Os membros da comunidade científica brasileira tem hoje mais uma tarefa: lutar para mudar o ensino de informativo para transformador e criativo. Este desafio é uma tarefa gigantesca, pois abarca todos os níveis de ensino sem privilegiar um em detrimento de outro. Para que se atinjam os objetivos de alterar o sistema educacional, é preciso concentrar esforços na formação dos professores. O Plano Nacional de Educação, elaborado pelo Congresso Nacional, desenha corretamente a formação do magistério, calcando-a na pesquisa como princípio orientador. Os professores de todos os níveis precisam estar conscientes de que a ciência não é só um conjunto de conhecimentos, mas sim um paradigma pelo qual se vê o mundo. Para colocar o sistema educacional em novo patamar, próprio do novo século que se inicia, o professor deverá ser um orientador de seus alunos no processo da descoberta e da reflexão crítica. Logo, a pesquisa educacional precisa ser ampliada, 
pois as experiências educacionais nem sempre podem ser transportadas de uma realidade sociocultural para outra, exigindo que sejam estimuladas por investimentos apropriados.

Percebe-se na fala da autora a urgência em se romper com um ensino memorístico, que as academias privilegiem a formação e não se reduza a informação, e que a ciência seja compreendida como uma forma de ver o mundo, o que resulta que, de acordo com a maneira que se vê o mundo seus processos de construção vão nesta direção. Logo, é necessário saber como vai se formar este professor para que ele, educado cientificamente, também eduque seu aluno, fazendo-o ver de modo diferente o mundo.

A educação para esse público não deve ser neutra apolítica e isenta das responsabilidades sociais e de humanização. Trata-se de uma educação dialógica em que deve haver "amor e humildade" (FREIRE, 2002, p.80). O diálogo e a dialogicidade baseados nessas condições são essências em uma educação como prática da liberdade, numa educação ancorada nos princípios da educação popular. Liberdade que requer incessante busca, que é uma conquista e não uma doação (FREIRE, 2002, p.34). Uma liberdade que possibilite a criação, a admiração e a capacidade de aventurar-se (FREIRE, 2002, p.55).

O diálogo é uma relação de encontro interativo e reflexivo entre os homens mediados pelos artefatos do mundo para ser mais (FREIRE, 2002, p.82), ou seja, reconhecer o outro como sujeito, como homem, aceitando-o como é, ultrapassando a troca de conceitos e aproximando-se da troca de sentidos e significados que alimentam a consciência. Isto é, deveríamos entender o diálogo não como uma técnica apenas, mas o momento em que os seres humanos se encontram para refletir sua realidade tal como a fazem e refazem (FREIRE, SHOR, 1986).

A conscientização possibilita o povo a inserir-se no processo histórico, como sujeito, evita os fanatismos e o inscreve na busca de sua afirmação (FREIRE, 2002). Para que o diálogo se estabeleça, é preciso uma relação de credibilidade entre os sujeitos.

[...] os homens se educam em comunhão, mediatizados pelo mundo. Mediatizados pelos objetos cognoscíveis que, na prática "bancária", são possuídos pelo educador que os descreve ou os deposita nos educandos passivos (FREIRE, 2002, p.69.). 


\section{Revista Eletrônica do Curso de Pedagogia trinerarius Reflectionism Reflectionis $155 \mathrm{~s}: 1807 \cdot 9342$}

Freire (2002) também nos mostra que a relação dialógica como fenômeno humano se faz pela ação e a reflexão, que se dão simultaneamente como dimensões solidárias que configuram o homem, conforme suas palavras, "Não é no silêncio que os homens se fazem, mas na palavra, no trabalho, na ação-reflexão" (FREIRE, 2002, p.78).

O autor salienta que nessa ação e reflexão emerge a ação criadora do homem ligada a sua práxis, uma vez que:

[...] os homens que, através de sua ação sobre o mundo, criam o domínio da cultura e da história, está em que somente estes são seres da práxis. Práxis que, sendo reflexão e ação verdadeiramente transformadora da realidade, é fonte de conhecimento reflexivo e criação. [...] os homens, simultaneamente, criam a história e se fazem seres histórico-sociais. (FREIRE, 2002, p.92).

Em sua pedagogia da autonomia, aprendemos com Paulo Freire a inconclusão do ser, sua necessária inserção na sociedade por meio de uma prática educativa que não desvincule o saber da ciência da prática social. Em sua pedagogia do oprimido, aprendemos a complexidade de se superar a situação de opressão na qual se encontra o oprimido e as possibilidades abertas pela presença do outro e pela sua palavra, quando essa significa pronunciar o mundo, na busca de transformá-lo.

Uma educação dialógica cuja ênfase não se coloca na transmissão de conteúdos, mas na formação de um sujeito capaz de compreender e atuar criticamente na sociedade se consolida como um fundamento da educação.

Nessa perspectiva, não raramente o ensino e o aprendizado de ciências para esse público, se limitam a métodos prescritos que se refazem continuamente na intenção de depositar no educando conceitos e teorias que o afastam de um ensino capaz de abarcar significados e sentidos.

Os currículos desde o ensino fundamental até o superior estão desenhados para que os estudantes memorizem um vasto número de fatos, não relacionados com sua vida diária. Freire (1967) “A partir das relações do homem com a realidade, resultantes de estar com ela e de estar nela, pelos atos da criação, re-criação e decisão, vai dinamizando o seu mundo. E, na medida em que cria, recria e decida, vão se transformando as épocas históricas". Por isso, desde já se saliente a necessidade de uma permanente atitude crítica, único modo pelo qual o 


\section{Revista Eletrônica do Curso de Pedagogia trinerarius Reflectionsm

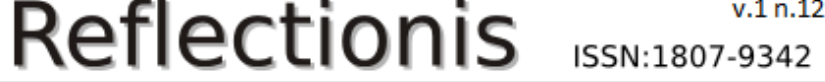

homem realizará a sua vocação natural para integrar-se. Necessitávamos de uma educação para a decisão, para a responsabilidade social e política.

Decorrente disso, reivindica-se uma escola transformadora, liberando a criatividade e a alegria da descoberta, de forma a possibilitar um ensino instigante e desafiador por meios de novos métodos de Educação Científica. Reivindica-se uma escola que ensine o aluno a pensar e refletir, que seja uma agência de cultura, de desenvolvimento da cidadania e de mudanças (WERTHEIN e CUNHA, 2005).

O papel do professor, nesse contexto, faz-se necessário ser repensado, considerando a mudança significativa que estamos reivindicando. Uma educação que possibilitasse ao homem a discussão corajosa de sua problemática. Educação que o colocasse em diálogo constante com o outro. Que o identificasse com métodos e processos científicos. Considerando que hoje fica difícil entender o mundo em que vivemos sem o conhecimento dos princípios básicos da ciência e da tecnologia, "é fundamental aumentar o capital humano da nossa população através de uma Educação Científica voltada para o aprender como apreender" (TOFFLER, 1970).

A inconclusão do ser, a inserção dos saberes científicos na prática social, a presença do outro e de sua palavra, a pronunciar e transformar o mundo são elementos da pedagogia freireana que qualificam nossa compreensão de Educação Científica. Essa compreensão qualificada passa pelo resgate do conhecimento prévio do educando, pela busca de um aprendizado de conhecimentos científicos a partir de temas que se relacionem com os contextos de vida dos educandos, que sejam objeto de uma pesquisa realizada coletivamente e que confira especialmente ao educando a possibilidade de compartilhar o que pesquisou e aprendeu.

O modelo que ocorre hoje parece deixar evidente que o processo através do qual acontecem as situações onde é transmitida a educação favorece ainda mais injustamente os sujeitos. O ensino que temos conduz os sujeitos a continuarem cada vez mais dominados para aceitarem as relações de desigualdade, mas podemos ser capazes de compreender a realidade em que estamos inseridos e então modificá-la na busca de transformações. Uma alternativa de mudança que poderia ser direcionada é de uma educação que busque cada vez mais propiciar que a Ciência seja um instrumento da leitura de realidade e facilitadora da aquisição de uma 


\section{Revista Eletrônica do Curso de Pedagogia ttinerarius Reflectionism

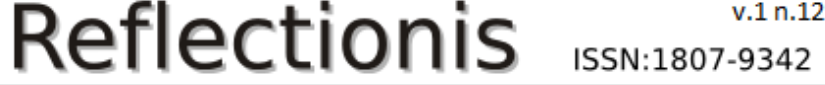

visão crítica e, assim, possa contribuir para qualificá-la. De modo que, a História da Ciência esteja presente em nossas aulas, transformando as nossas avaliações em atividades onde haja participação dos alunos. Assim, estaremos fazendo uma educação mais política, contribuindo para que tenhamos homens ainda mais questionadores, conseguindo, então, novas possibilidades para a legitimação da Educação Científica.

Em uma Educação Científica suficientemente capaz de se aproximar das particularidades do ensino e das expectativas geradas para um público, vislumbramos uma educação formadora, em que o sujeito é capaz de dialogar com as informações científicas que norteiam seu contexto de vida. Os conceitos e conteúdos são carregados de sentido e significados, eles não se fecham em delimitações conceituais desconectados do todo. Assim, uma Educação Científica de professores privilegia primeiramente uma abertura para a compreensão desses conceitos científicos em constante processo de reelaboração e ressignificação, a partir de situações e contextos que dialogam e aproximam o educador e educando de seu cotidiano.

\section{Referências}

ALBAGLI, Sarita. Divulgação científica: informação científica para a cidadania? Ciência da Informação, Brasília, v. 25, n. 3, p. 396-404, set./dez. 1996.

AMABIS, José Mariano. A premência da Educação Científica. In: WERTHEIN, Jorge; CUNHA, Célio da (Orgs.) Educação Científica e desenvolvimento: o que pensam os cientistas. Brasília: UNESCO, Instituto Sangari, 2005.

CACHAPUZ, A.; PRAIA, J.; JORGE, M. Da educação em ciências às orientações para o ensino de ciências: um repensar epistemológico. Ciência e Educação, São Paulo, v.10, n. 3, p. $363-381,2004$.

CHASSOT, Attico. Alfabetização científica: uma possibilidade para a inclusão social. Revista Brasileira de Educação. Jan/Fev/Mar/Abr N No 22, 2003. p. 89-100.

COLLINS, H. A comunidade científica em tempos de disputa. In: GIL, F. (Coord.). A ciência tal qual se faz. Lisboa: Sá da Costa, 1999. p. 53-64.

FREIRE, P. Educação como prática de liberdade. Rio Janeiro, Ed. Paz e Terra, 1967.

FREIRE, Paulo; SHOR, Ira. Medo e Ousadia: cotidiano do professor. tradução de Adriana Lopez. - Rio de Janeiro: Paz e Terra, 1986.

FREIRE, Paulo. Pedagogia do oprimido. 34. ed. São Paulo: Paz e Terra, 2002.

FREIRE, Paulo. Pedagogia da autonomia: saberes necessários à prática docente. São Paulo: Paz e Terra, 2003. 
GOLDEMBERG, José. Educação Científica para quê? In: WERTHEIN, Jorge; CUNHA, Célio da (Orgs.) Educação Científica e desenvolvimento: o que pensam os cientistas. Brasília: UNESCO, Instituto Sangari, 2005.

MOURA, G.R.S.; VALE, J.M.F. do. O ensino de ciências na $5^{\mathrm{a}}$ e na $6^{\mathrm{a}}$ séries da escola fundamental. In: NARDI, R. (Orgs.) Educação em ciências: da pesquisa á prática docente. São Paulo: Escrituras, 2003.

ROITMAN, Isaac. Educação científica: quando mais cedo melhor. Brasília: RITLA, 2007. Disponível em: http://www.ritla.net/index.php?option=com_content\&task=view\&id=2151\&Itemid=236.

TOFFLER, A. Future Shock. Toronto Bantam Book, 1970. UNESCO. Primary and Secondary Education: age-specific enrolment ratios by gender 1960/61-1995/96 (www.unesco.org).

VILANOVA, Rita; e MARTINS, Isabel. Educação em Ciências e educação de jovens e adultos: pela necessidade do diálogo entre campos e práticas. Ciência e Educação, v. 14, n. 02, 2008. p. 331-346.

ZANCAN, Glaci Therezinha. Educação científica uma prioridade nacional. São Paulo em perspectiva, São Paulo, v. 14 n. 1, 2000.p. 01-07.

ZIMAN, J. A ciência na sociedade moderna. In: GIL, F. (Coord.). A Ciência tal qual se faz. Lisboa: Sá da Costa, 1999. p. 437-450

WERTHEIN, Jorge; CUNHA, Célio da. A Educação Científica como direito de todos. In: WERTHEIN, Jorge; CUNHA, Célio da (Orgs.) Educação Científica e desenvolvimento: o que pensam os cientistas. Brasília: UNESCO, Instituto Sangari, 2005. 